\title{
Real-Time Control Strategy of Elman Neural Network for the Parallel Hybrid Electric Vehicle
}

\author{
Ruijun Liu, Dapai Shi, and Chao Ma \\ School of Transportation and Vehicle Engineering, Shandong University of Technology, No. 12 Zhangzhou Road, \\ Zibo, Shandong 255049, China \\ Correspondence should be addressed to Dapai Shi; sdapai@163.com
}

Received 15 April 2014; Revised 30 June 2014; Accepted 1 July 2014; Published 26 August 2014

Academic Editor: H. R. Karimi

Copyright (C) 2014 Ruijun Liu et al. This is an open access article distributed under the Creative Commons Attribution License, which permits unrestricted use, distribution, and reproduction in any medium, provided the original work is properly cited.

Through researching the instantaneous control strategy and Elman neural network, the paper established equivalent fuel consumption functions under the charging and discharging conditions of power batteries, deduced the optimal control objective function of instantaneous equivalent consumption, established the instantaneous optimal control model, and designs the Elman neural network controller. Based on the ADVISOR 2002 platform, the instantaneous optimal control strategy and the Elman neural network control strategy were simulated on a parallel HEV. The simulation results were analyzed in the end. The contribution of the paper is that the trained Elman neural network control strategy can reduce the simulation time by $96 \%$ and improve the real-time performance of energy control, which also ensures the good performance of power and fuel economy.

\section{Introduction}

Under the dual pressure of environmental pollution and energy crisis, hybrid vehicles have advantages of both conventional vehicles and electric vehicles, which have characteristics of energy conservation, environmental protection, diverse shapes, and strong implementation. Hybrid vehicles have become an effective way to solve the problem of energy crisis and environmental protection and also have been one of the most perspective vehicle models.

According to different connective ways of power system, hybrid electric vehicle (HEV) can be mainly divided into four styles: series, parallel, series-parallel, and complex. The dynamic structure diagram is shown in Figure 1.

Engine output energy of series HEV is transformed two times and the efficiency of the motor and generator is relatively low, so series HEV loses more energy and leads to lower efficiency than vehicles of internal combustion engine. Parallel HEV (PHEV) is equipped with series and parallel power systems, and their structures and control systems are more complex and have higher cost. Complex HEV structures and control systems are most complex and have highest cost. However, parallel hybrid power system can adapt to various road conditions and is widely used by enterprises $[1,2]$.

As the core of multiple energy control system, the energy control strategy determines performances of PHEV. Based on vehicle's torque, energy control strategies of PHEV are mainly divided into four types $[3,4]$ : static logic threshold energy control strategy, instantaneous optimal energy control strategy, global optimal energy control strategy, and neural network energy control strategy. The static logic threshold control strategy cannot guarantee the optimal fuel economy of PHEV, does not adapt to dynamic conditions, and cannot make the whole system to achieve maximum efficiency. Besides, its threshold parameters are set by engineering experience $[5,6]$. The global optimal control strategy can achieve global optimal fuel consumption of HEV. Its defects are complex algorithm, large amount of calculation, and knowing the whole condition in advance $[7,8]$. Neural network energy control strategy can adapt to diverse conditions with good robustness and obtain global fuel consumption optimum by engineering experience $[9,10]$. Instantaneous optimal energy control strategy can realize minimum equivalent fuel consumption of PHEV in each control cycle which is widely used to distribute PHEV energy [11]. 


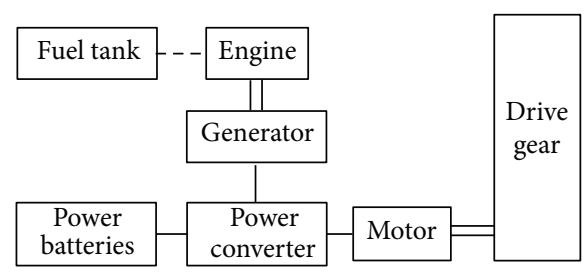

Series hybrid electric vehicle

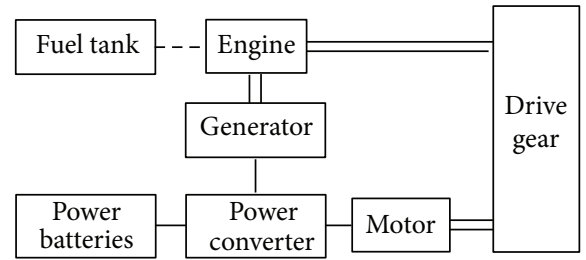

Series-parallel hybrid electric vehicle

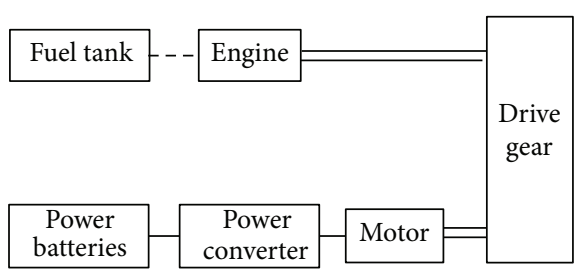

Parallel hybrid electric vehicle

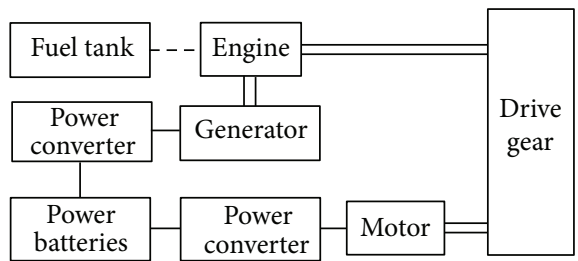

Complex hybrid electric vehicle

-- - Oil-way connection

$=$ Mechanical connection

— Electrical connection

FIgURE 1: Classification of hybrid electric vehicles.

The basic principle of instantaneous optimal control strategy is based on the model of the optimal curve of engines; the object function of the whole power system was optimized on the specific operating points of parallel HEV. On the basis of the instantaneous optimal operating points, it makes power of variable states redistributed and make the loss of energy minimized in the energy flow process at any time (see Figure 2). Instantaneous optimal control strategy has good fuel economy at any time and bad real-time performance. Its real-time performance is influenced by these factors which are the accuracy of various components battery ages and engine and motor characteristics [12-14]. So it is difficult to improve the real-time performance of instantaneous optimal control strategy by changing these factors.

The hybrid vehicles possess good power performance and fuel economy and obtain rapid allocation energy by finding a new energy control strategy. Elman neural network is a feedback neural network and has a very strong computing ability and stability [15]. The instantaneous rules of the instantaneous optimal control strategy are used to train Elman neural network, establish Elman neural network controller, and improve the real-time performance of energy control [14-16].

Based on the research of the instantaneous optimal control strategy, the strategy possesses good fuel economy and makes energy distributed reasonably. However, its realtime performance is poor. In order to solve bad real-time defects of instantaneous control strategy, instantaneous optimal control rules are used to train the Elman neural network control strategy and improve the real-time performance of the trained Elman energy control strategy on the premise that it can guarantee advantages of the instantaneous optimal control strategy. The results show that the trained Elman neural network control strategy can replace the instantaneous

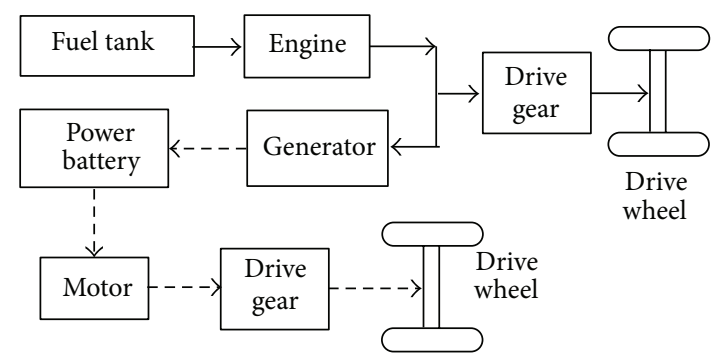

FIGURE 2: Energy flow diagram of parallel hybrid electric vehicles.

optimal control strategy, optimize power distribution, and make the simulation time reduced by $60 \%$.

\section{Research Energy Control Strategy}

2.1. Instantaneous Optimal Control Strategy. Instantaneous optimal control strategy is defined as follows. In order to achieve the minimum fuel consumption of HEV, the optimal output power of the engine and electric motor is calculated in each control cycle of hybrid power system. Working conditions of HEV and calculation expressions of the equivalent fuel consumption are different in every time. So an optimal objective function should be established [17]. Working condition of hybrid system is divided into two cases of power battery charging and discharging. Then, objective functions of the instantaneous equivalent minimum fuel consumption were established on two working conditions.

Here, the full line represents the circulation and transformation of fuel chemical energy in the hybrid power system. The dotted line represents electric current circulation and transformation in the hybrid power system. 
2.1.1. Calculate the Equivalent Fuel Consumption of Battery Discharging. When the power battery takes part in driving hybrid cars, its SOC value will reduce and deviate from the target of SOC value. In order to compensate for the used electricity and restore SOC value of power batteries, the engine drives the motor to charge power batteries in the future time [18]. The charging time is divided into $n$ control cycles, and the motor power of each cycle is $P_{\text {mc_chg_ } i}(i=$ $1,2,3 \ldots, n)[5]$.

The relationship between the motor power $\left(P_{\mathrm{mc}}\right)$ with driving vehicle and the motor power $\left(P_{\text {mc_chg }_{-} i}\right)$ with power batteries charging is

$$
P_{\mathrm{mc}}=\bar{\eta}_{\mathrm{mc}}{ }^{2} \bar{\eta}_{\text {dischg }} \bar{\eta}_{\mathrm{chg}} \sum_{i=1}^{n} P_{\mathrm{mc} \_ \text {chg } i},
$$

where $\bar{\eta}_{\mathrm{mc}}$ is the average efficiency of motor; $\bar{\eta}_{\mathrm{chg}}$ is the average efficiency of power battery charging; $\bar{\eta}_{\text {dischg }}$ is the average efficiency of power battery discharging.

When the motor drives the vehicle, the energy consumption of power batteries can be converted into the engine fuel consumption. The equivalent fuel consumption rate of the motor is

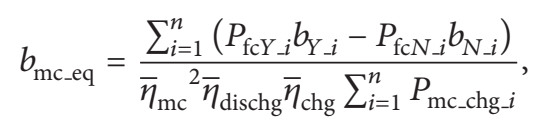

where $P_{\mathrm{fcN} i}$, when the engine does not charge power batteries, is the engine power of the $i$ control period; $b_{N i}$, when the engine does not charge power batteries, is the fuel consumption rate of the engine; $P_{\mathrm{fc} Y} i$, when the engine charges power batteries, is the engine power of the $i$ control period; $b_{Y j}$, when the engine charges power batteries, is the fuel consumption rate of the engine.

Let $\bar{b}_{\text {chg }}$ be the average fuel consumption rate when the engine charges power batteries:

$$
\bar{b}_{\mathrm{chg}}=\sum_{i=1}^{n} \frac{P_{\mathrm{fCY} \_i} b_{Y_{i} i}-P_{\mathrm{fcN}_{-} i} b_{\mathrm{N}_{-} i}}{P_{\mathrm{mc} \_ \text {chg } i}} .
$$

Merge (3) and (2):

$$
b_{\text {mceq }}=\frac{\bar{b}_{\text {chg }}}{\bar{\eta}_{\text {mc }}{ }^{2} \bar{\eta}_{\text {dischg }} \bar{\eta}_{\text {chg }}} .
$$

When the motor drives the vehicle after a period of $\Delta t$, equivalent instantaneous fuel consumption of the motor is

$$
m_{\text {mc_eq }}=\frac{\bar{b}_{\text {chg }} P_{\text {mc }}}{\bar{\eta}_{\text {mc }}{ }^{2} \bar{\eta}_{\text {dischg }} \bar{\eta}_{\text {chg }}} .
$$

2.1.2. Calculate the Fuel Consumption of Batteries Charging. When the power battery is charged by the engine, its SOC value will rise and even exceed the target of the SOC value. In order to maintain SOC values, power battery energy will be consumed in future [18]. Discharging time is divided into $n$ control cycles, and the motor power of the each control cycle is $P_{\mathrm{mc2} i}(i=1,2,3 \ldots, n)$ [17].
In a certain period of discharging time, the relationship between motor power $\left(P_{\mathrm{mc2} i}\right)$ with driving vehicle and motor power $\left(P_{\text {mc_chg_ } 2}\right)$ with charging power batteries is

$$
\sum_{i=1}^{n} P_{\mathrm{mc} 2 i}=P_{\mathrm{mc} \_ \text {chg } 2} \bar{\eta}_{\mathrm{mc} 2}{ }^{2} \bar{\eta}_{\mathrm{chg} 2} \bar{\eta}_{\text {dischg2 } 2}
$$

where $P_{\text {mc_chg2 }}$ is the motor power when the power battery is charged; $\bar{\eta}_{\mathrm{mc2}}$ is the average efficiency of motor; $\bar{\eta}_{\mathrm{chg} 2}$ is the average efficiency of the power battery charging; $\bar{\eta}_{\text {dischg } 2}$ is the average efficiency of the power battery discharging.

When the motor drives the vehicle, the relationship between the motor power battery energy consumption and the fuel consumption rate is

$$
b_{\text {mc_eq2 } 2}=\frac{P_{\mathrm{fc} Y 2} b_{\mathrm{Y} 2}-P_{\mathrm{fcN} 2} b_{\mathrm{N} 2}}{P_{\mathrm{mc} \_ \text {chg } 2} \bar{\eta}_{\mathrm{mc2} 2} \bar{\eta}_{\mathrm{chg} 2} \bar{\eta}_{\text {dischg } 2}},
$$

where $P_{\mathrm{fcY} 2}$, when the engine charges the power battery, is the power of the engine; $b_{Y 2}$, when the engine charges the power battery, is the fuel consumption rate of the engine; $P_{\mathrm{fcN} 2}$, when the engine does not charge the power battery, is the power of the engine; $b_{N 2}$, when the engine does not charge the power battery, is the fuel consumption rate of the engine.

Let $b_{\text {chg } 2}$ be the fuel consumption rate when the engine charges the power battery:

$$
b_{\mathrm{chg} 2}=\frac{P_{\mathrm{fc} Y 2} b_{\mathrm{Y} 2}-P_{\mathrm{fcN} 2} b_{\mathrm{N} 2}}{P_{\mathrm{mc} \_ \text {chg } 2}} .
$$

Simplify the (8) formula:

$$
b_{\text {mceq2 } 2}=\frac{b_{\text {chg2 }}}{\bar{\eta}_{\text {mc2 } 2}{ }^{2} \bar{\eta}_{\text {dischg } 2} \bar{\eta}_{\text {chg2 }}} .
$$

When the motor charges power batteries after a period of $\Delta t$, the objective function of equivalent instantaneous fuel consumption of the motor is

$$
m_{\text {mc_eq2 } 2}=\frac{\bar{b}_{\text {chg2 }} P_{\text {mc_chg2 }}}{\bar{\eta}_{\text {mc2 } 2}{ }^{2} \bar{\eta}_{\text {dischg2 } 2} \bar{\eta}_{\text {chg2 }}} .
$$

2.1.3. Deduce the Objective Function of the Instantaneous Optimal Control Strategy. Set two new variables:

$f_{\text {eq_dischg }}=\frac{\bar{b}_{\text {chg }}}{\bar{\eta}_{\text {mc }}{ }^{2} \bar{\eta}_{\text {dischg }} \bar{\eta}_{\text {chg }}}, \quad f_{\text {eq_chg }}=\frac{b_{\text {chg2 } 2}}{\bar{\eta}_{\text {mc2 }}{ }^{2} \bar{\eta}_{\text {dischg } 2} \bar{\eta}_{\text {chg2 }}}$,

where $b_{\text {chg2 }}$ is the fuel consumption rate when the engine charges power batteries at the present moment; $\bar{b}_{\text {chg }}$ is the average fuel consumption rate when the engine charges power batteries in the future time.

The instantaneous control objective function of the lowest fuel consumption is

$$
\begin{aligned}
M=\sum \operatorname{Min}\{ & m_{\mathrm{fc}}\left[T_{\mathrm{fc}}(t), \omega(t)\right] \Delta t \\
& \left.+m_{\text {mc_eq }}\left[T_{\mathrm{mc}}(t), \omega_{\mathrm{mc}}(t)\right] \Delta t\right\},
\end{aligned}
$$


where $\omega_{\mathrm{fc}}(t)$ is engine speed; $\omega_{\mathrm{mc}}(t)$ is motor speed; $T_{\mathrm{fc}}$ is output torque of the engine; $T_{\mathrm{mc}}$ is output torque of the motor. Consider

$$
\begin{aligned}
& m_{\text {mc_eq }}\left[P_{\mathrm{mc}}(t)\right] \\
& = \begin{cases}f_{\text {eq_dischg }} P_{\mathrm{mc}} & T_{\mathrm{mc}}>0 \text { (power batteries discharge) } \\
f_{\text {eq_chg }} P_{\mathrm{mc} \_ \text {chg2 }} & T_{\mathrm{mc}}<0 \text { (power batteries charge) } .\end{cases}
\end{aligned}
$$

$P_{\mathrm{mc}}$ and $P_{\mathrm{mc} \text { chg2 }}$ are both motor power, so they can be unified as $P_{\mathrm{mc}}$. By calculating, the improved instantaneous control objective function of the minimum fuel consumption is

$$
\begin{aligned}
M=\sum \operatorname{Min} & \left\{m_{\mathrm{fc}}\left[P_{\mathrm{fc}}(t)\right] \Delta t\right. \\
& \left.+\left[\lambda f_{\text {eq_dischg }}+(1-\lambda) f_{\text {eq_chg }}\right] P_{\mathrm{mc}} \Delta t\right\},
\end{aligned}
$$

where $\lambda=\left(1+\operatorname{sign}\left(T_{\mathrm{mc}}\right)\right) / 2$.

2.1.4. Improve the Objective Function of the Instantaneous Optimal Control Strategy. SOC value change of batteries and braking energy recovery both have a certain effect on energy control. The optimal function of the working point needs to be improved.

(1) Revise the SOC Value Function of Power Batteries. When power batteries work, their SOC value is maintained at the high efficient range by the reset function, in order to reduce the loss energy in the process of charging and discharging power batteries and make hybrid system keep better performances. The working principle of SOC reset function is as follows. When the SOC value is more than the target region, the hybrid power system will give priority to consuming power battery energy. It does not stop until SOC value decreases to the target region under the effect of the reset function. When the battery SOC value is lower than the target region, the hybrid system will give priority to consuming fuel energy to drive the vehicle and recover the value of SOC. It does not stop until SOC value returns to the target region under the effect of the reset function.

Set $K_{\mathrm{SOC}}$ be the variable in the reset function, and the value table between $K_{\mathrm{SOC}}$ and SOC value is shown in Table 1.

Based on the Matlab platform and Table 1 data, the fitting curve between $K_{\mathrm{SOC}}$ and SOC value is constructed by using fitting curve toolbox, as shown in Figure 3.

Polynomial function of the fitting curve is

$$
\begin{aligned}
K_{\mathrm{soc}}= & -8866 x^{7}+33460 x^{6}-52310 x^{5}+43730 x^{4} \\
& -21010 x^{3}+5766 x^{2}-833.5 x+49.77
\end{aligned}
$$

where $x$ : is SOC value.
TABLE 1: The value table between $K_{\mathrm{soc}}$ and SOC.

\begin{tabular}{lcccccc}
\hline SOC & 0.11 & 0.14 & 0.2 & 0.25 & 0.3 & 0.35 \\
$K_{\text {soc }}$ & 7 & 2 & 1.05 & 1.05 & 1.03 & 1.04 \\
SOC & 0.4 & 0.45 & 0.5 & 0.55 & 0.59 & 0.64 \\
$K_{\text {soc }}$ & 1.02 & 1.02 & 1 & 0.99 & 0.98 & 0.96 \\
SOC & 0.7 & 0.74 & 0.81 & 0.85 & 0.9 & \\
$K_{\text {soc }}$ & 0.96 & 0.94 & 0.94 & 0.8 & 0.2 & \\
\hline
\end{tabular}

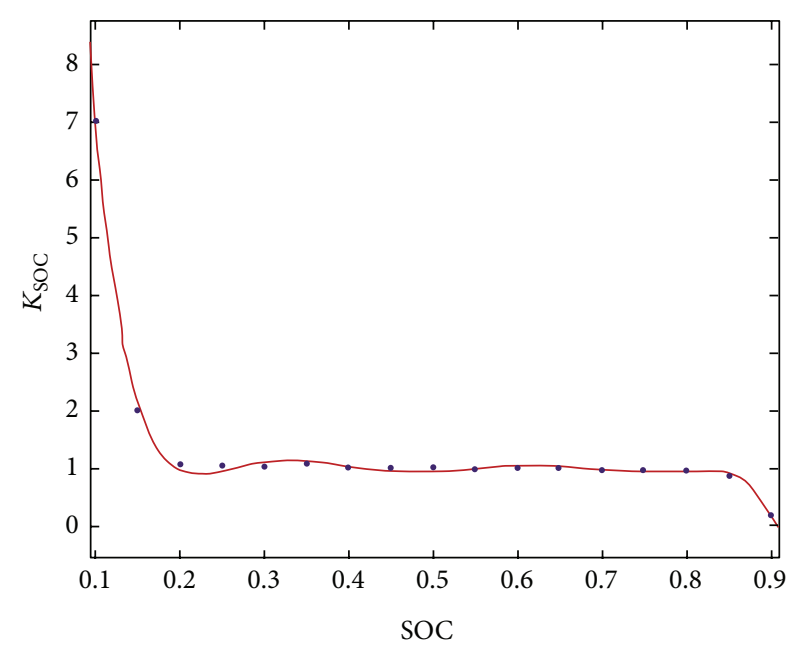

FIGURE 3: SOC and $K_{\text {SOC }}$ relationship curve.

Considering the influence of power battery SOC, the formula of instantaneous equivalent fuel consumption of HEV can be expressed as $K_{\text {soc }} m_{\text {mceeq }}$.

(2) Revise the Objective Function of Braking Recovery Energy. The adopted method which revises the equivalent fuel consumption function of power battery energy is as follows: the average braking power is calculated at a period of time before the current moment. The power is used as the standard of fuel consumption correction of the braking recovery power in the next moment [19-22].

The statistical time range is divided into $n(n>0)$ cycles. In each cycle, let braking power be a fixed value. Therefore, the average braking power of the whole time can be expressed as

$$
\bar{P}_{\text {braking }}=\frac{\sum_{i=1}^{n} P_{\text {braking } i}}{n} .
$$

When power batteries discharge, the objective function of instantaneous equivalent fuel consumption is

$$
m_{\text {mc_eq }}=\frac{\bar{b}_{\text {chg }}\left(P_{\text {mc }}+\bar{P}_{\text {braking }}\right)}{\bar{\eta}_{\mathrm{mc}}{ }^{2} \bar{\eta}_{\text {dischg }} \bar{\eta}_{\text {chg }}} .
$$

In summary, taking the influence of power battery SOC and brake energy recovery into consideration, the final 


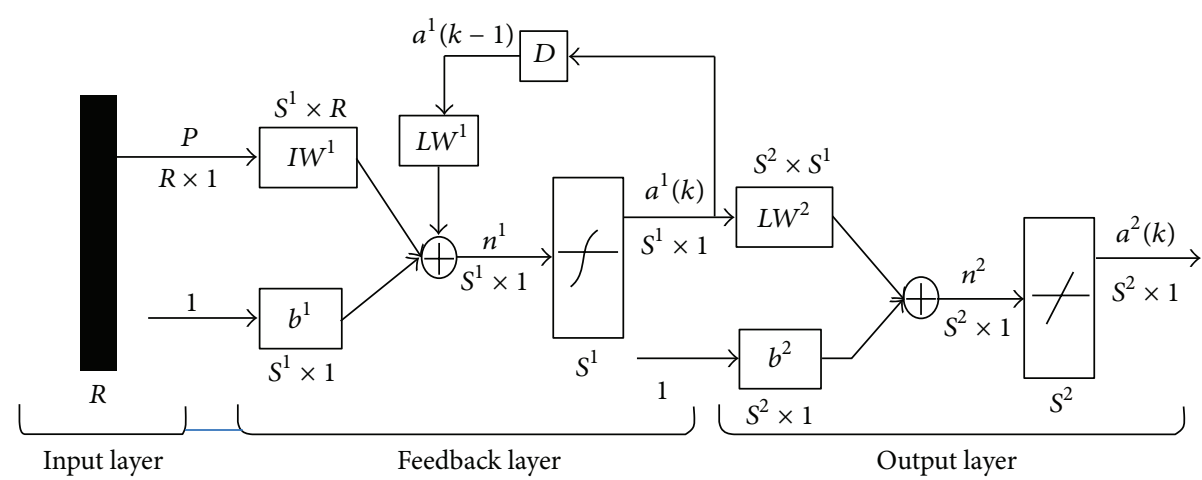

FIGURE 4: Elman neural network model.

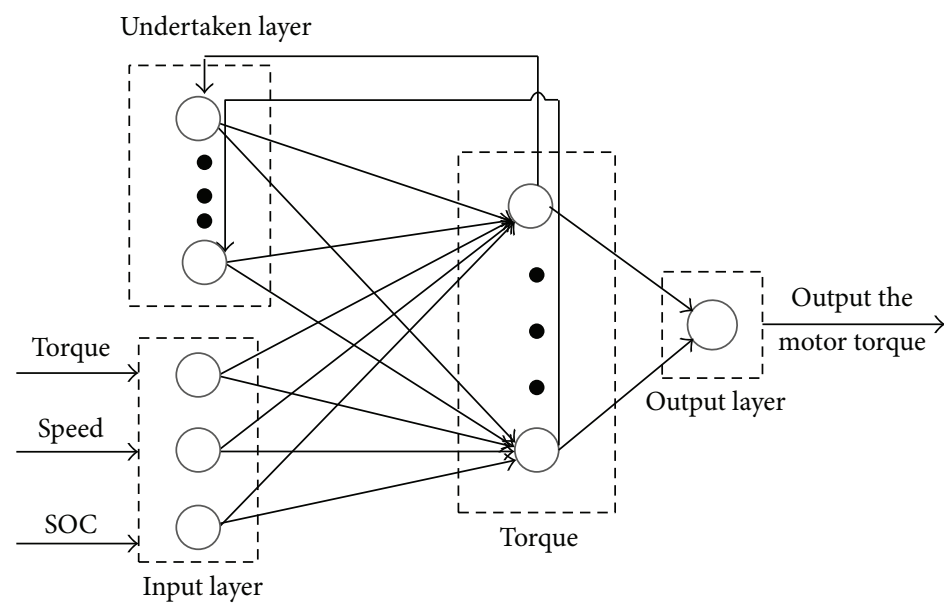

FIGURE 5: Structure diagram of Elman neural network.

objective function of instantaneous optimal control strategy is

$$
\begin{aligned}
M=\sum \operatorname{Min} & \left\{m_{\mathrm{fc}}\left[P_{\mathrm{fc}}(t)\right] \Delta t\right. \\
& \left.+K_{\text {soc }} m_{\text {mc_eq }}\left[P_{\mathrm{mc}}(t)+\bar{P}_{\text {braking }}(t)\right] \Delta t\right\} .
\end{aligned}
$$

\subsection{Elman Neural Network Control Strategy}

2.2.1. The Structure of Elman Neural Network. Elman neural network is put forward by Jeffrey L. Elman in 1990 and is a typical local recessionary grid, as shown in Figure 4 [23].

$P$ is the input of the neural network and its size is $R \times 1$; $b^{1}$ is the neuronal threshold vector of the feedback layer and its size is $S^{1} \times 1 ; I W^{1}$ is the connective weight vector of the neurons and the input vector in the input layer and its size is $S^{1} \times R ; n^{1}$ is the middle operational result of the neurons in the feedback layer, namely, weighted sum of the connective weight vector and the threshold vector, and its size is $S^{1} \times 1$; $a^{1}$ is the output vector of the feedback layer's neuron in the $K$ iteration and its size is $S^{1} \times 1 ; D$ is feedback node. It is the same way that $b^{2}, L W^{2}, n^{2}$, and $a^{2}$ are related to parameters of the output layer.

The inputs of structure diagram of Elman neural network is the required torque, speed, and SOC value of power battery and its output is motor torque. The structure diagram of Elman neural network is shown in Figure 5 [24].

The structure diagram of Elman neural network contains input layer, hidden layer, undertaken layer, and output layer. Let the input vector of the input layer be three-dimensional vector $u$; the output vector of the output layer is onedimensional vector $y$; the output vector of the hidden layer is $n$-dimensional vector $x$; the output vector of the undertaken layer is $n$-dimensional vector $r ; w^{1}, w^{2}$, and $w^{3}$ are respective connective weights of the hidden layer to the output layer, the input layer to the hidden layer, and the undertaken layer to the hidden layer; $g(\cdot)$ is the driving function of the output neurons; $f(\cdot)$ is the driving function of hidden layer; $h(\cdot)$ is the driving function of undertaken layer; net $(\cdot)$ is the net input driving function of a certain layer; $A$ shows the input layer; $B$ shows the undertaken layer; $K$ shows the iterative sequence.

Define two functions:

$$
\begin{gathered}
v_{i}(k)= \begin{cases}u_{n}(k), & \text { if } i \in A, \\
r_{n}(k), & \text { if } i \in B,\end{cases} \\
w^{i}(k)= \begin{cases}w^{2}, & \text { if } i \in A, \\
w^{3}, & \text { if } i \in B .\end{cases}
\end{gathered}
$$


The input and output functions of the $N$ neuron of the hidden layer are

$$
\begin{aligned}
\operatorname{net}_{n}(k+1) & =\sum_{i \in A \cup B} w^{i}(k) v_{i}(k), \\
x_{n}(n+1) & =f\left(\operatorname{net}_{n}(k+1)\right) .
\end{aligned}
$$

The input and output functions of the $N$ neuron of the hidden layer are

$$
\begin{gathered}
\operatorname{net}_{n}(k)=\sum_{i \in A \cup B} w^{i}(k-1) v_{i}(k-1), \\
r(k)=h\left(\operatorname{net}_{n}(k)\right) .
\end{gathered}
$$

The input and output functions of the output layer's neuron are

$$
\begin{gathered}
\operatorname{net}_{n}(k+1)=\sum_{i \in A \cup B} w^{i}(k+1) x_{n}(k+1), \\
y(k+1)=g(\operatorname{net}(k+1)) .
\end{gathered}
$$

2.2.2. Select the Parameters of Elman Neural Network. The neuron number is determined by following formula [25]:

$$
k=\sqrt{m+n}+\beta,
$$

where $m$ is the number of the input vector; $n$ is the neuron number of the output vector; $\beta$ is a constant, (1 10).

The excitation function of Elman neural network of the feedback layer selects the Tansig function [26]:

$$
\tan \operatorname{sig}(x)=\frac{2}{1+e^{-2 x}}-1
$$

2.2.3. Learning and Training Mechanism of Elman Neural Network. Elman neural network is trained by LevenbergMarquardt algorithm. The error index function of LevenbergMarquardt arithmetic is

$$
E(w)=\frac{1}{2} \sum_{i=1}^{p}\left\|y_{i}-y_{i}^{\prime}\right\|^{2}=\frac{1}{2} \sum_{i=1}^{p} e_{i}^{2}(w),
$$

where $p$ is the sample number; $e^{i}$ is the systemic error; $y_{i}^{\prime}$ is the actual output of the network.

The formula of the adjusting weight is

$$
w^{k+1}=w^{k}+\Delta w .
$$

The computing formula of the increment weight is

$$
\Delta w=\left[J^{T}(w) J(w)+u I\right]^{-1} J^{T}(w) e(w),
$$

where $u$ is learning rate; $I$ is the unit matrix; $J(w)$ is the Jacobian matrix. Consider

$$
J(w)=\left[\begin{array}{cccc}
\frac{\partial e_{1}(w)}{\partial w_{1}} & \frac{\partial e_{1}(w)}{\partial w_{2}} & \cdots & \frac{\partial e_{1}(w)}{\partial w_{n}} \\
\frac{\partial e_{2}(w)}{\partial w_{1}} & \frac{\partial e_{2}(w)}{\partial w_{1}} & \cdots & \frac{\partial e_{2}(w)}{\partial w_{n}} \\
\vdots & \vdots & \ddots & \vdots \\
\frac{\partial e_{n}(w)}{\partial w_{1}} & \frac{\partial e_{n}(w)}{\partial w_{2}} & \cdots & \frac{\partial e_{n}(w)}{\partial w_{n}}
\end{array}\right]
$$

Neural network weight is adjusted by the LevenbergMarquardt algorithm, and the adjusting process is shown in Figure 6.

\section{Modeling of Energy Control Strategy}

3.1. Modeling of Instantaneous Optimal Control Strategy. On the platform of Matlab/simulink, the instantaneous control model is established and mainly includes two parts: the calculation model of average braking energy of recovered power and the calculative model of optimal working point $[25,26]$.

First, the calculation model of average braking energy of the recovery power is established as shown in Figure 7. Inputs of the model are the required torque and rotational speed and its output is the calculated average recovery power of braking energy in the transmission system.

Second, the calculation model of the revised SOC value of power battery is established, as shown in Figure 8. The model can maintain the SOC value of power batteries at a high efficient range.

Third, the calculation model of the optimal operating point is established, as shown in Figure 9. Inputs of the model are the required torque, rotational speed, modified $S_{\text {target-motor }}$ value of power batteries, and the average braking recovery power and the output torque of the motor is the optimal allocation power between the engine and motor in the transmission system.

Finally, the whole simulation diagram of the instantaneous control strategy is established, as shown in Figure 10.

3.2. The Elman Neural Network Model. Elman neural network is gradually learning to do something by imitating human brain. Its essence is to improve the learned knowledge and the neurons weight [27-30]. The flow diagram of the trained Elman neural network is shown in Figure 11.

\section{Simulation Results and Analysis}

The basic vehicle parameters are shown in Table 2 .

Traffic parameters of simulation experiments are described in Table 3.

The original control model is replaced by the instantaneous optimal control model in ADVISOR 2002. Then the trained Elman neural network controller is imported to the software [31, 32].

Simulation results are shown in Figure 13. HWFET_mdf and NEDC_mdf show simulation results of the instantaneous optimal control strategy of the PHEV model (Figure 12); HWFET_net and NEDC_net show simulation results of the Elman neural network controller of the PHEV model.

Compared with the instantaneous optimal control strategy, the Elman neural network strategy can slow down the decline of SOC value and maintain SOC value at high efficient range on the NEDC working condition in Figure 13(a). Meanwhile, the Elman neural network strategy has approximate SOC value change compared with the instantaneous optimal control strategy on the HWFET working in Figure 13(b). 


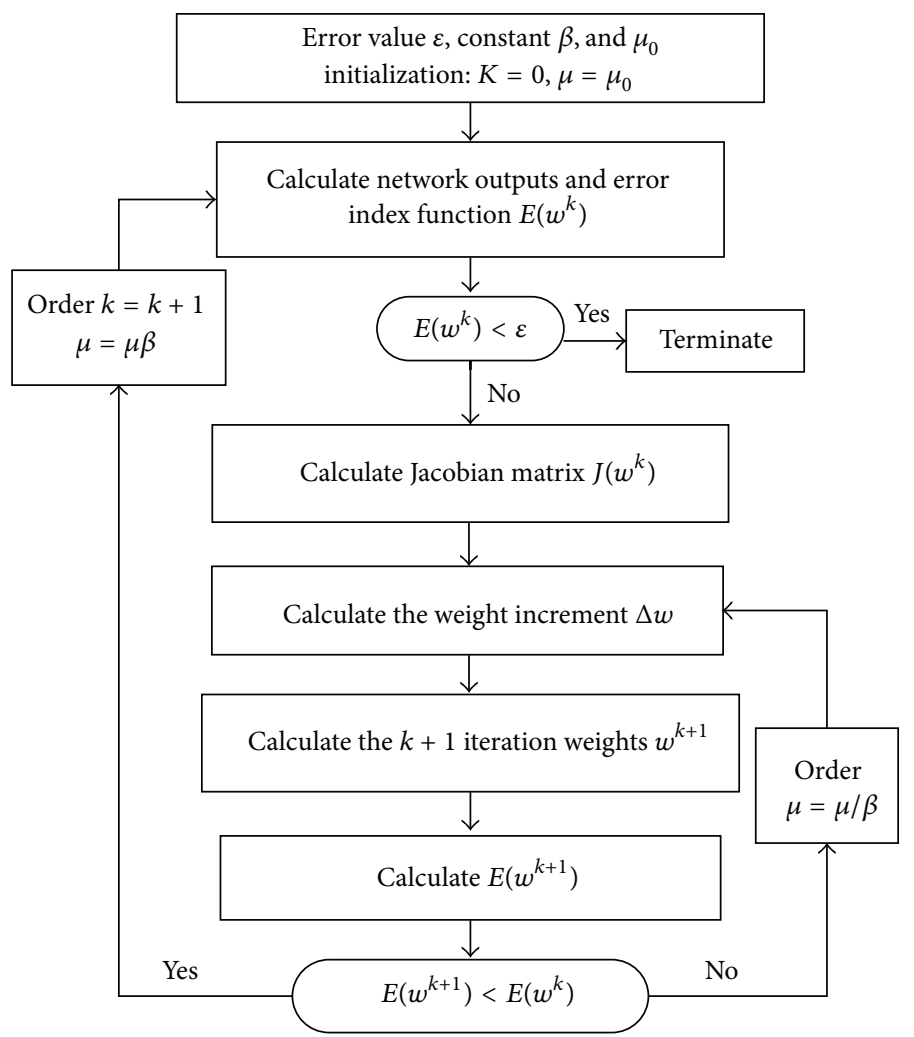

FIGURE 6: Process map of the adjusting network weight.

TABLE 2: Parallel hybrid electric vehicle parameters.

\begin{tabular}{lc}
\hline Vehicle & \\
Curb weight & $1605 \mathrm{~kg}$ \\
Face area & $2.65 \mathrm{~m}^{2}$ \\
Wheel base & $2.775 \mathrm{~m}$ \\
Height of the center of mass & $0.5 \mathrm{~m}$ \\
Front axle load distribution ratio & 0.51 \\
Coefficient drag & 0.32 \\
Engine & \\
Peak power & $118 \mathrm{~kW}$ \\
Displacement & $2.5 \mathrm{~L}$ \\
Power battery pack & \\
Voltage & $244.8 / 650 \mathrm{~V}$ \\
Style & $\mathrm{NI}-\mathrm{MH}$ \\
Volume & $6.5 \mathrm{Ah}$ \\
Mold number & 34 \\
Motor & \\
Peak power & $105 \mathrm{~kW}$ \\
Style & PMSM \\
\hline
\end{tabular}

As shown in Figure 13(a), Elman neural network strategy can make the engine produce more torque than the instantaneous optimal control strategy at the beginning of $600 \mathrm{~s}$ on the NEDC working condition. It can make the vehicle start, accelerate, and climb better. After the vehicle starts, the two control strategies play the same role on the
TABLE 3: Traffic parameters of simulation experiments.

\begin{tabular}{lcc}
\hline Parameter & NEDC & HWFET \\
\hline Idle time $(\mathrm{s})$ & 298 & 6 \\
Top speed $(\mathrm{km} / \mathrm{h})$ & 10.93 & 16.51 \\
Cycle time $(\mathrm{s})$ & 1184 & 765 \\
Average speed $(\mathrm{km} / \mathrm{h})$ & 33.21 & 77.58 \\
Maximum acceleration $\left(\mathrm{m} / \mathrm{s}^{2}\right)$ & 1.06 & 1.43 \\
Maximum deceleration $\left(\mathrm{m} / \mathrm{s}^{2}\right)$ & -1.39 & -1.48 \\
Park time $($ time $)$ & 13 & 1 \\
Traveling distance $(\mathrm{km})$ & 120 & 96.4 \\
\hline
\end{tabular}

vehicle energy control. As seen in Figure 13(b), Elman neural network strategy can make the engine produce slightly more torque than instantaneous optimal control strategy on the HWFET working condition, while these two strategies have similar effect on the engine torque control.

As seen in Figure 15, Elman neural network strategy can make motor produce slightly more torque than the instantaneous optimal control strategy at some moments on the NEDC and HWFET working condition, while the two strategies have the similar effect on the motor torque control.

As shown in Table 4, compared with the instantaneous optimal neural strategy, fuel consumption of Elman neural network strategy only increases about $0.5(\mathrm{~L} / 100 \mathrm{~km})$ on the NEDC and HWFEF working condition, which implies that Elman neural network controller can also have the 


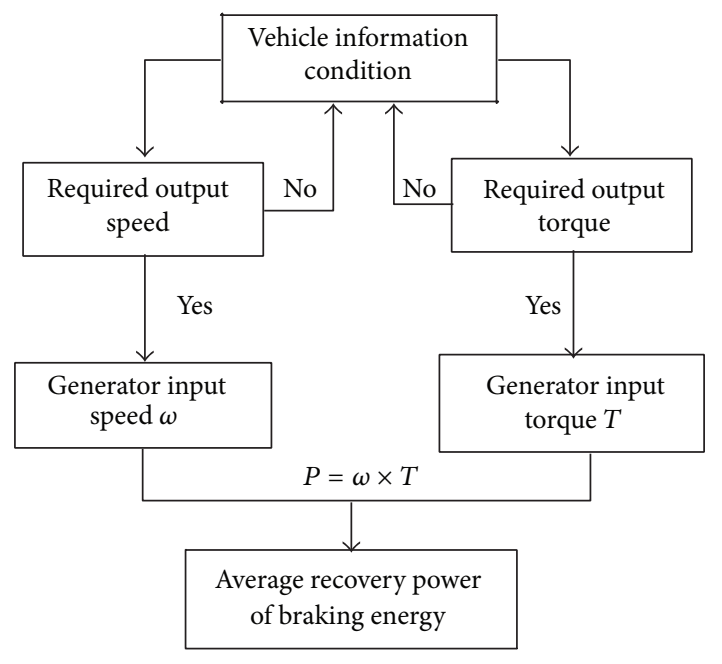

FIGURE 7: Flow diagram of average recovery power of braking energy.

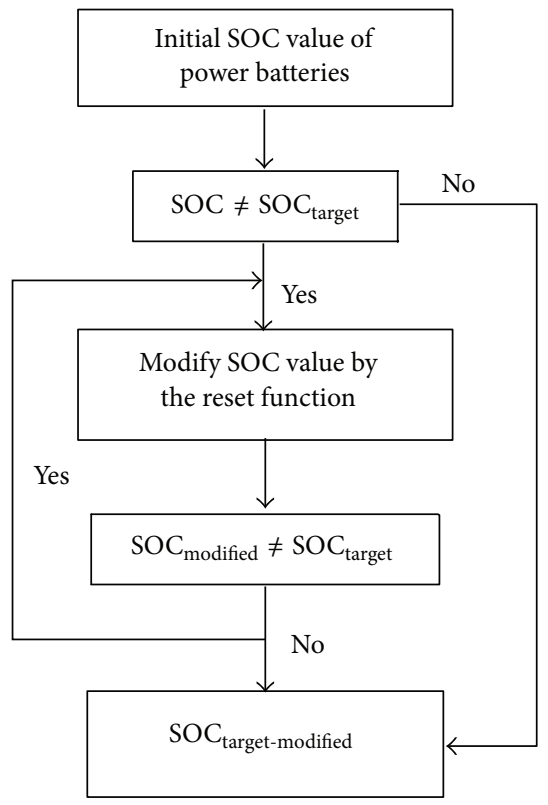

FIGURE 8: Flow diagram of the revised SOC value of power batteries.

TABLE 4: Fuel consumption of $100 \mathrm{~km}(\mathrm{~L} / 100 \mathrm{~km})$.

\begin{tabular}{lcc}
\hline Strategy & \multicolumn{2}{c}{ Road } \\
& NEDC & HWFEF \\
\hline Instantaneous optimal control & 9.4 & 6.5 \\
Elman neural network & 9.8 & 7 \\
\hline
\end{tabular}

advantage of low fuel consumption. The slight increase in fuel consumption can be accepted since it has a little effect on the fuel economy of the whole vehicle. As seen in Table 5, Elman neural network strategy makes the simulation time decreased greatly compared with the instantaneous optimal neural strategy and improves the response time of the vehicle greatly.

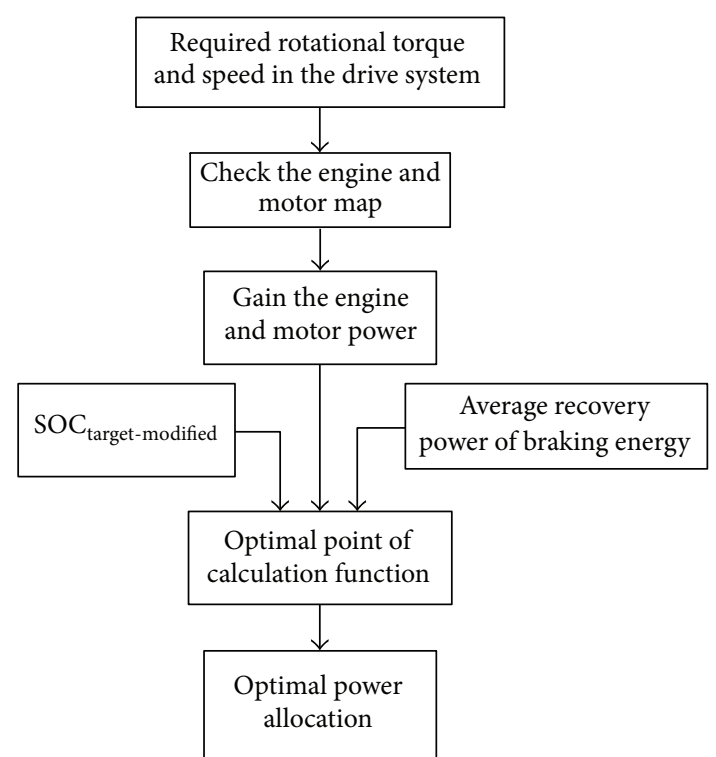

FIGURE 9: Flow diagram of the optimal operating point.

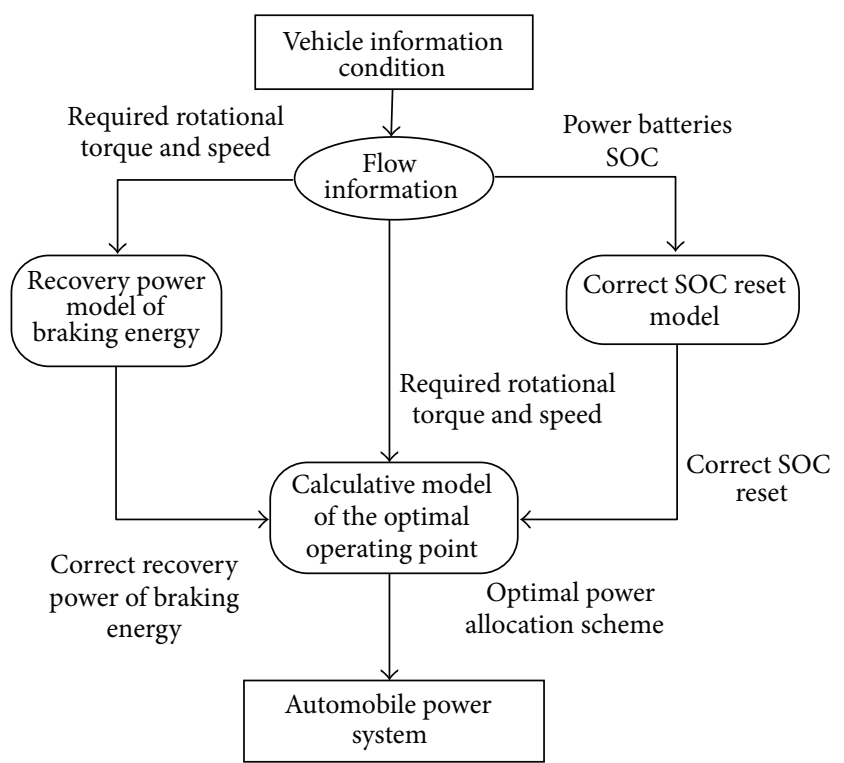

FIGURE 10: Total simulation diagram of the instantaneous control strategy.

TABLE 5: Simulation time (s).

\begin{tabular}{lcc}
\hline Strategy & \multicolumn{2}{c}{ Road } \\
& NEDC & HWFEF \\
\hline Instantaneous optimal control & 471.3 & 315.8 \\
Elman neural network & 15.6 & 10.2 \\
\hline
\end{tabular}

In conclusion, as seen in Figures 13, 14, and 15, Elman neural network strategy can replace the instantaneous optimal control strategy to maintain SOC value at the high efficient range and achieve a reasonable distribution of the torque between the engine and the motor. The significance of the 


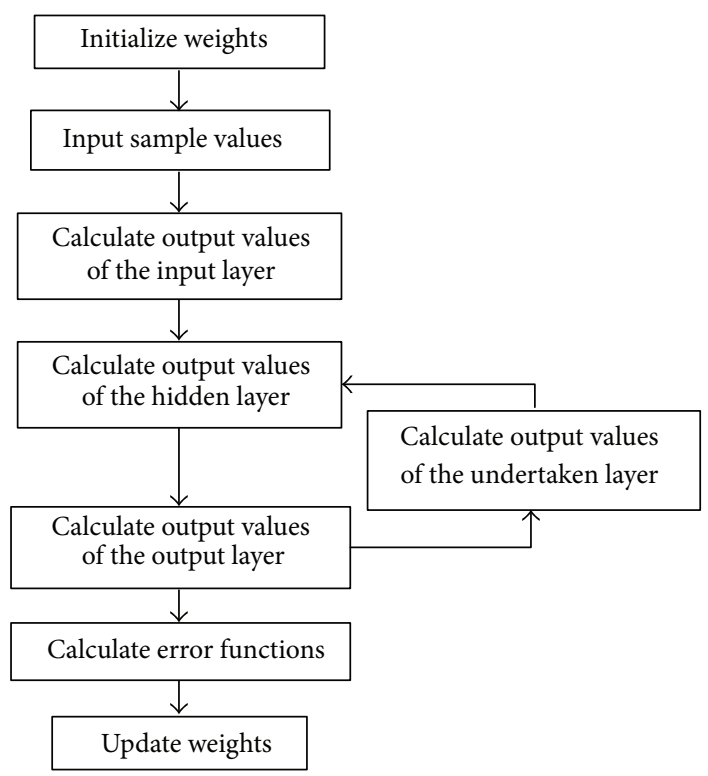

FIGURE 11: The training flow diagram of the trained Elman neural network.

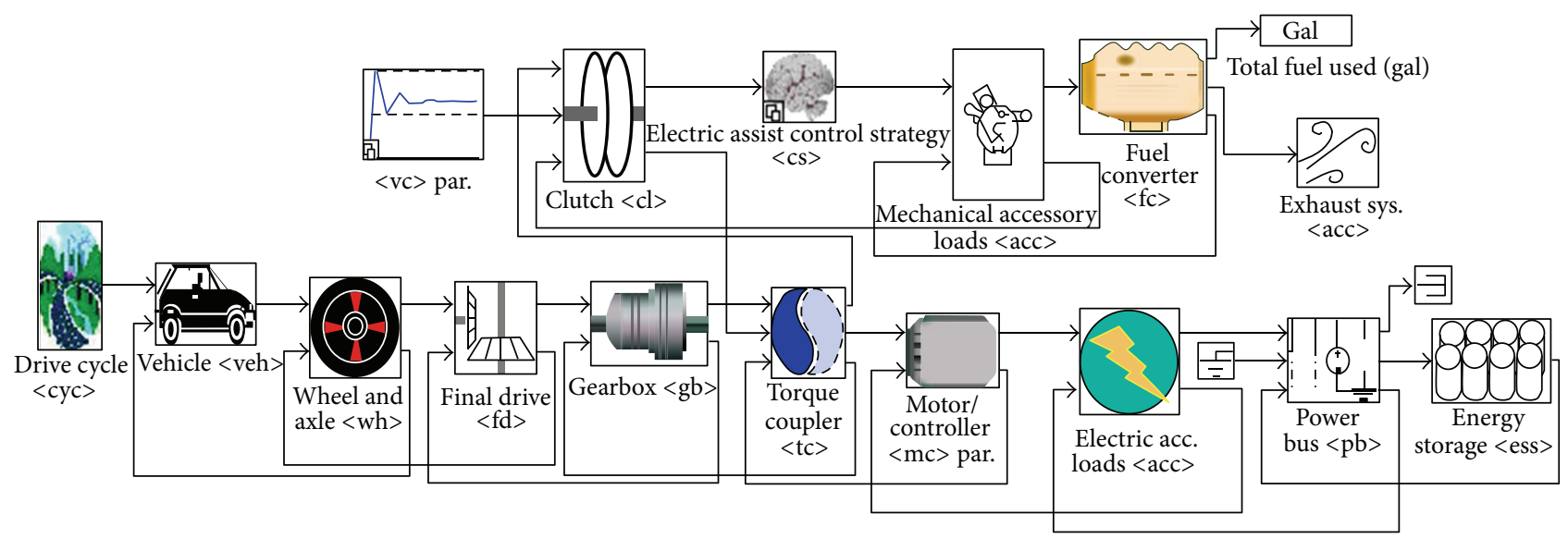

FIGURE 12: Simulation model of the parallel hybrid electric vehicle.

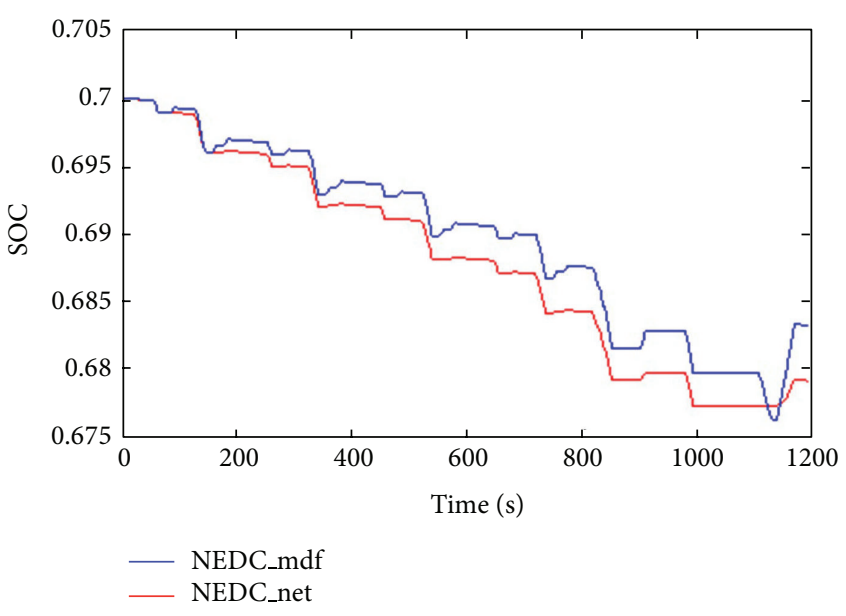

(a) NEDC working condition

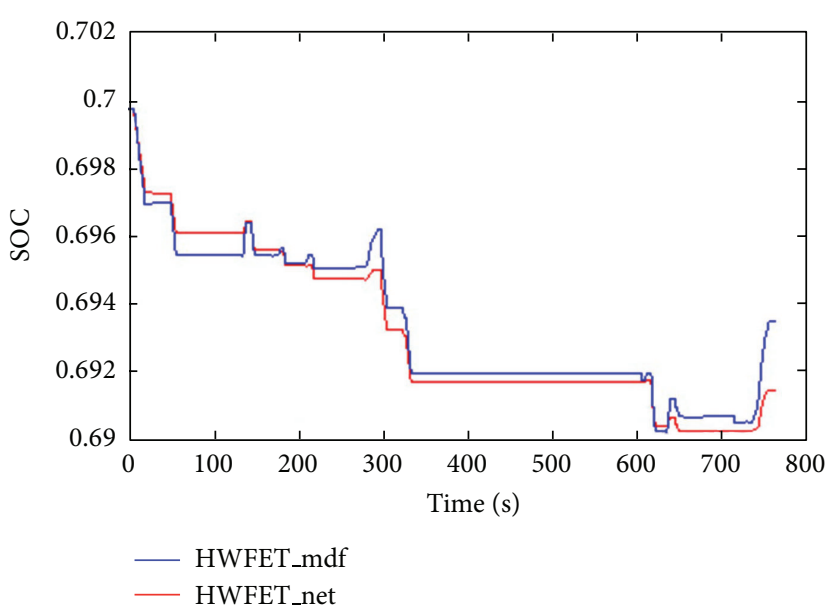

(b) HWFET working condition

FIGURE 13: Contrast power battery SOC. 


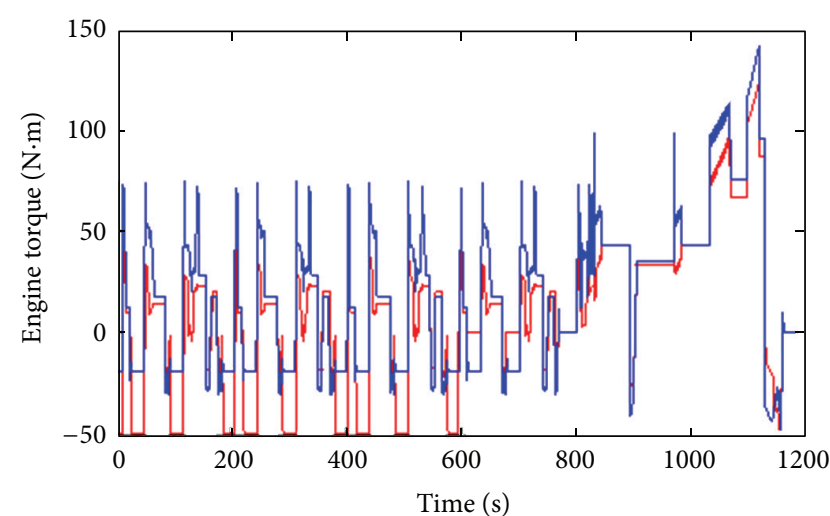

- NEDC_mdf - NEDC_net

(a) NEDC working condition

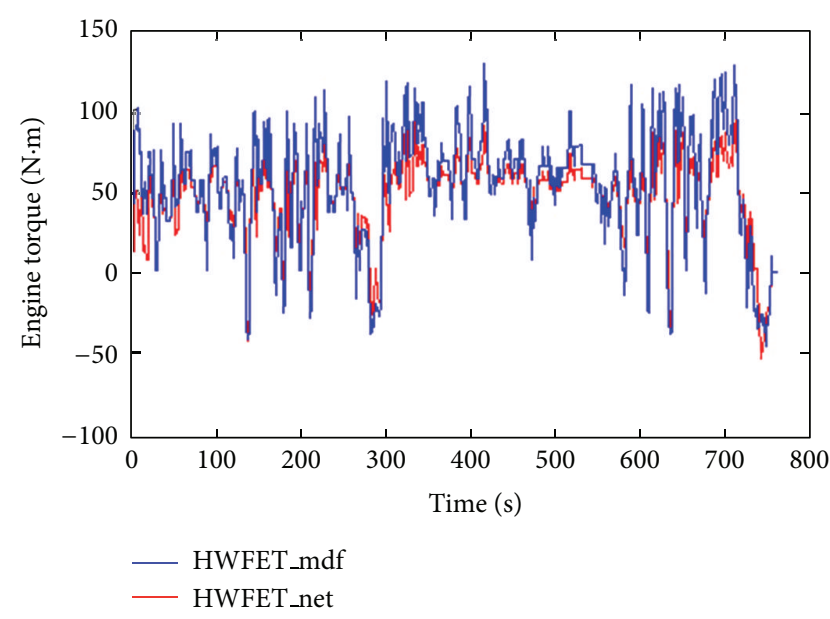

(b) HWFET working condition

FIGURE 14: Contrast engine torque.

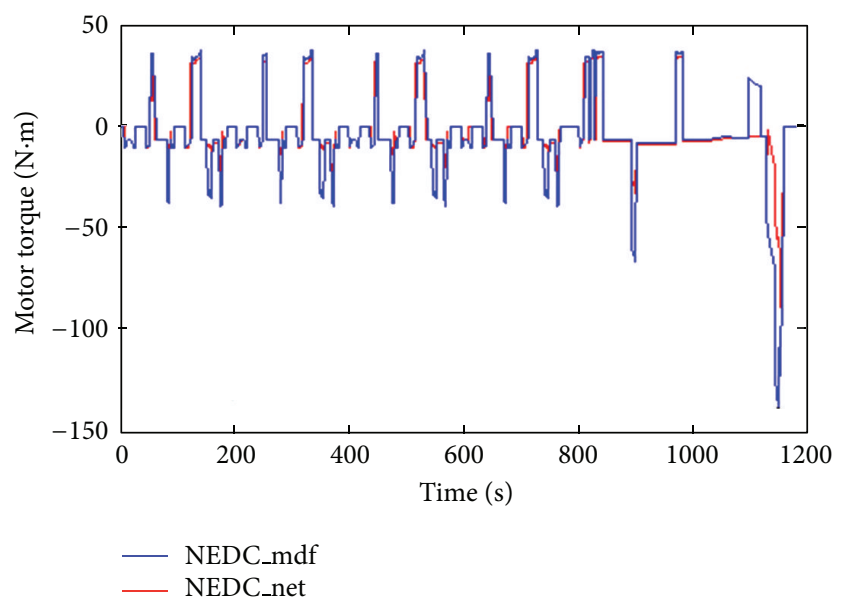

(a) NEDC working condition

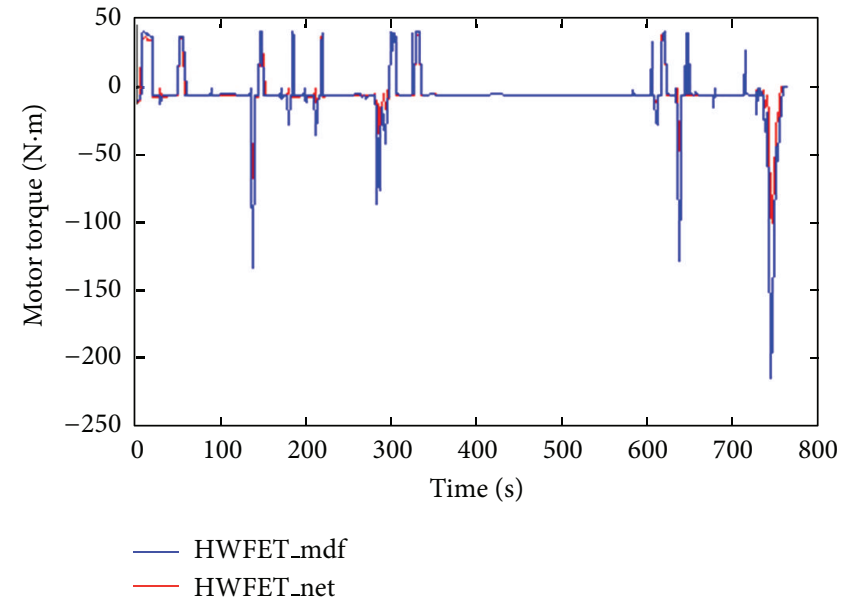

(b) HWFET working condition

Figure 15: Contrast the motor torque.

paper is that the simulation time of energy control is reduced by $96 \%$.

\section{Conclusion}

Through the research on the instantaneous optimal strategy and Elman neural network control strategy, we deduce the objective functions of instantaneous optimal control and establish the instantaneous control model and design the Elman controller. Based on the ADVISOR 2002 platform, two control strategies were simulated on a hybrid electric vehicle.

It is seen from the simulation results that the trained Elman neural network strategy shows similar control ability on the vehicle energy distribution compared with the instantaneous optimal control strategy, which ensures good performances of power and fuel economy of $\mathrm{HEV}$, reduces the control reaction time greatly, and overcomes the disadvantage of poor real-time performance of the instantaneous optimal control strategy. The research significance of the paper is that the simulation time of energy control is reduced by $96 \%$.

Future works are listed as below.

(1) Simulation and experiment should be improved by adding more design parameters, such as vehicle emission.

(2) It is necessary to do lots of experiments to enrich simulation results.

(3) Actual road condition is more complex than the simulation road condition, so control strategies need to be tested in the actual road conditions.

\section{Conflict of Interests}

The authors declare that there is no conflict of interests regarding the publication of this paper. 


\section{References}

[1] S. G. Cui, Automotive Technology Of New Energy, Beijing University of Technology press, Beijing, China, 2009.

[2] R. Hodkinson and J. Fentos, Lightweight Electric/Hybrid Vehicle Design, SAE International, Warrendale, Pa, USA, 2001.

[3] J. Wu, Optimization of energy management strategy for parallel hybrid electric vehicle [Ph.D. thesis], Shang Dong University, Ji Nan, China, 2008.

[4] C. Lin, H. Peng, J. W. Grizzle, and J. Kang, "Power management strategy for a parallel hybrid electric truck," IEEE Transactions on Control Systems Technology, vol. 11, no. 6, pp. 839-849, 2003.

[5] T. Hofman, M. Steinbuch, R. van Druten, and A. Serrarens, "A Rule-based energy management strategies for hybrid vehicles," Electric and Hybrid Vehicles, vol. 1, no. 1, pp. 71-94, 2007.

[6] N. Jalil, N. A. Kheir, and M. Salman, "A rule-based energy management strategy for a series hybrid vehicle," in Proceedings of the American Control Conference, pp. 689-693, Albuquerque, NM, USA, 1997.

[7] S. Delprat, J. Lauber, T. M. Guerra, and J. Rimaux, "Control of a parallel hybrid powertrain: optimal control," IEEE Transactions on Vehicular Technology, vol. 53, no. 3, pp. 872-881, 2004.

[8] S. Delprat, T. M. Guerra, and J. Rimaux, "Optimal control of a parallel hybrid powertrain from global optimization to real time control strategy," in Proceedings of the 18th International Electric Vehicle Symposium, Berlin, Germany, 2001.

[9] M. H. Asemani and V. J. Majd, "Stability of output-feedback DPDC-based fuzzy synchronization of chaotic systems via LMI," Chaos, Solitons and Fractals, vol. 42, no. 2, pp. 1126-1135, 2009.

[10] G. D. Tian, J. W. Chu, Y. Lu, H. Ke, X. Zha, and G. Xu, "Expected energy analysis for industrial process planning problem with fuzzy time parameters," Computers \& Chemical Engineering, vol. 35, no. 12, pp. 2905-2912, 2011.

[11] G. Paganelli and S. Delprat, "Equivalent consumption minimization strategy for parallel hybrid powertrains," in Proceedings of the IEEE Vehicular Technology Conference, vol. 4, pp. 2076-2081, 2002.

[12] J. Park, Y. Park, and J. H. Park, "Real-time powertrain control strategy for series-parallel hybrid electric vehicles," SAE Paper 3172, 2007.

[13] A. Sciarretta, M. Back, and L. Guzzella, "Optimal control of parallel hybrid electric vehicle," IEEE, vol. 12, no. 3, pp. 352-363, 2004.

[14] J. Park, Y. Park, and J. H. Park, "Real-time powertrain control strategy for series-parallel hybrid electric vehicles," SAE Paper, vol. 1, no. 3172, 2007.

[15] H. R. Karimi and H. J. Gao, "New delay-dependent exponential $H_{\infty}$ synchronization for uncertain neural networks with mixed time delays," IEEE Transactions on Systems, Man, and Cybernetics B: Cybernetics, vol. 40, no. 1, pp. 173-185, 2010.

[16] R. Razavian, N. L. Azad, and J. Mcphee, "On real-time optimal control of a series Hybrid Electric Vehicle with an ultracapacitor," in Proceedings of the American Control Conference, pp. 547-552, 2012.

[17] D. Sinoquet, G. Rousseau, and Y. Milhau, "Design optimization and optimal control for hybrid vehicles," Optimization and Engineering, vol. 12, no. 1-2, pp. 199-213, 2011.

[18] G. Paganelli, G. Ercole, A. Brahma, Y. Guezennec, and G. Rizzoni, "General supervisory control policy for the energy optimization of charge-sustaining hybrid electric vehicles," JSAE Review, vol. 22, no. 4, pp. 511-518, 2001.
[19] W. H. Sun, H. J. Gao, and O. Kaynak, "Adaptive backstepping control for active suspension systems with hard constraints," IEEE/ASME Transactions on Mechatronics, vol. 18, no. 3, pp. 1072-1079, 2013.

[20] W. Sun, Z. Zhao, and H. Gao, "Saturated adaptive robust control for active suspension systems," IEEE Transactions on Industrial Electronics, vol. 60, no. 9, pp. 3889-3896, 2013.

[21] W. Sun, H. Gao Sr., and O. Kaynak, "Finite frequency $H_{\infty}$ control for vehicle active suspension systems," IEEE Transactions on Control Systems Technology, vol. 19, no. 2, pp. 416-422, 2011.

[22] W. Sun, Y. Zhao, J. Li, L. Zhang, and H. Gao, "Active suspension control with frequency band constraints and actuator input delay," IEEE Transactions on Industrial Electronics, vol. 59, no. 1, pp. 530-537, 2012.

[23] F. J. Lin, Y. C. Hung, and S. Y. Chen, "FPGA-based computed force control system using Elman neural network for linear ultrasonic motor," IEEE Transactions on Industrial Electronics, vol. 56, no. 4, pp. 1238-1253, 2009.

[24] G. Pajares, M. Guijarro, and A. Ribeiro, "A Hopfield Neural Network for combining classifiers applied to textured images," Neural Networks, vol. 23, no. 1, pp. 144-153, 2010.

[25] G. D. Tian, Y. M. Liu, Q. Z. Tian, and J. W. Chu, "Evaluation model and algorithm of product disassembly process with stochastic feature," Clean Technologies and Environmental Policy, vol. 14, no. 2, pp. 345-356, 2012.

[26] G. D. Tian, M. C. Zhou, J. W. Chu, and Y. M. Liu, “ Probability evaluation models of product disassembly cost subject to random removal time and different removal labor cost," IEEE Transactions on Automation Science and Engineering, vol. 9, no. 2, pp. 288-295, 2012.

[27] M. Zapateiro, N. Luo, H. R. Karimi, and J. Vehí, "Vibration control of a class of semiactive suspension system using neural network and backstepping techniques," Mechanical Systems and Signal Processing, vol. 23, no. 6, pp. 1946-1953, 2009.

[28] W. Pawlus, H. R. Karimi, and K. G. Robbersmyr, "Data-based modeling of vehicle collisions by nonlinear autoregressive model and feedforward neural network," Information Sciences, vol. 235, pp. 65-79, 2013.

[29] J. Guo and W. J. Sun, Neural Network Theory and the Realization of MATLAB7, Publishing House of Electronics Industry, Beijing, China, 2005.

[30] K. L. Zhou and Y. H. Kang, Neural Network Model and MATLAB Simulation Programming, Tsinghua University press, Beijing, China, 2005.

[31] T. Markel, A. Brooker, T. Hendricks et al., "ADVISOR: a systems analysis tool for advanced vehicle modeling," Journal of Power Sources, vol. 110, no. 2, pp. 255-266, 2002.

[32] X. H. Zeng and Q. N. Wang, "Develop control strategy model of hybrid electric vehicle based on ADVISOR2002," Automotive Engineering, vol. 26, no. 5, pp. 423-427, 2004. 


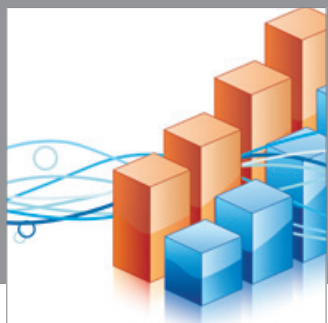

Advances in

Operations Research

mansans

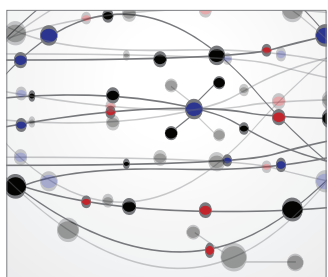

The Scientific World Journal
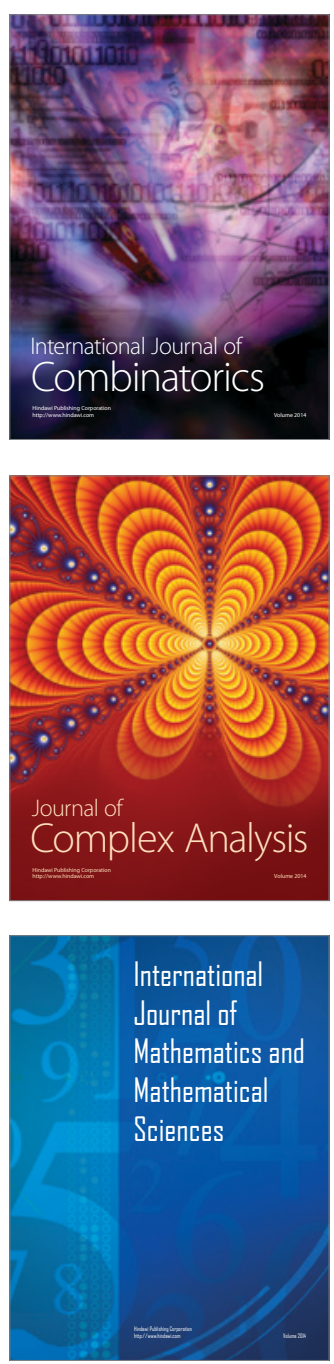
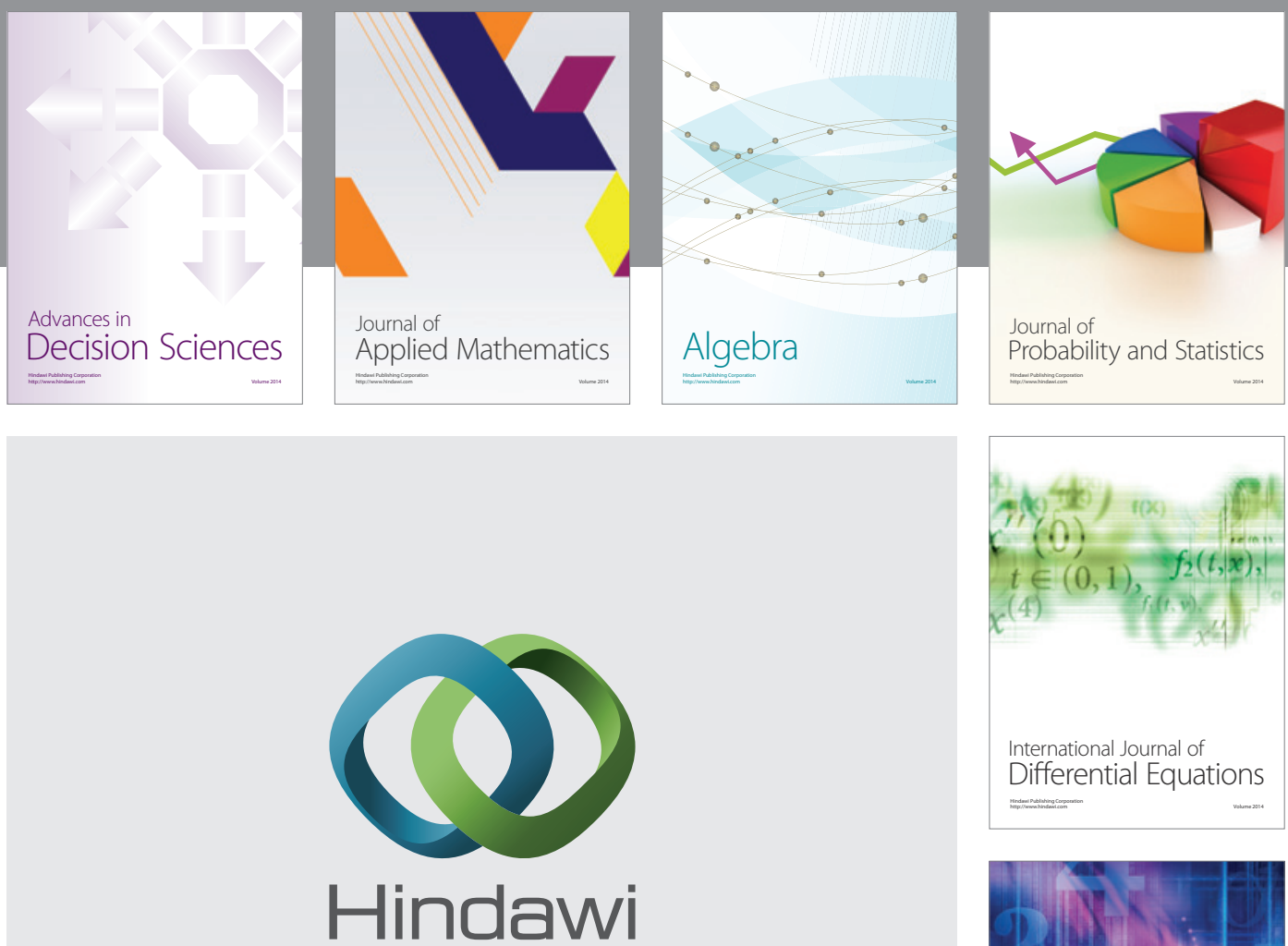

Submit your manuscripts at http://www.hindawi.com
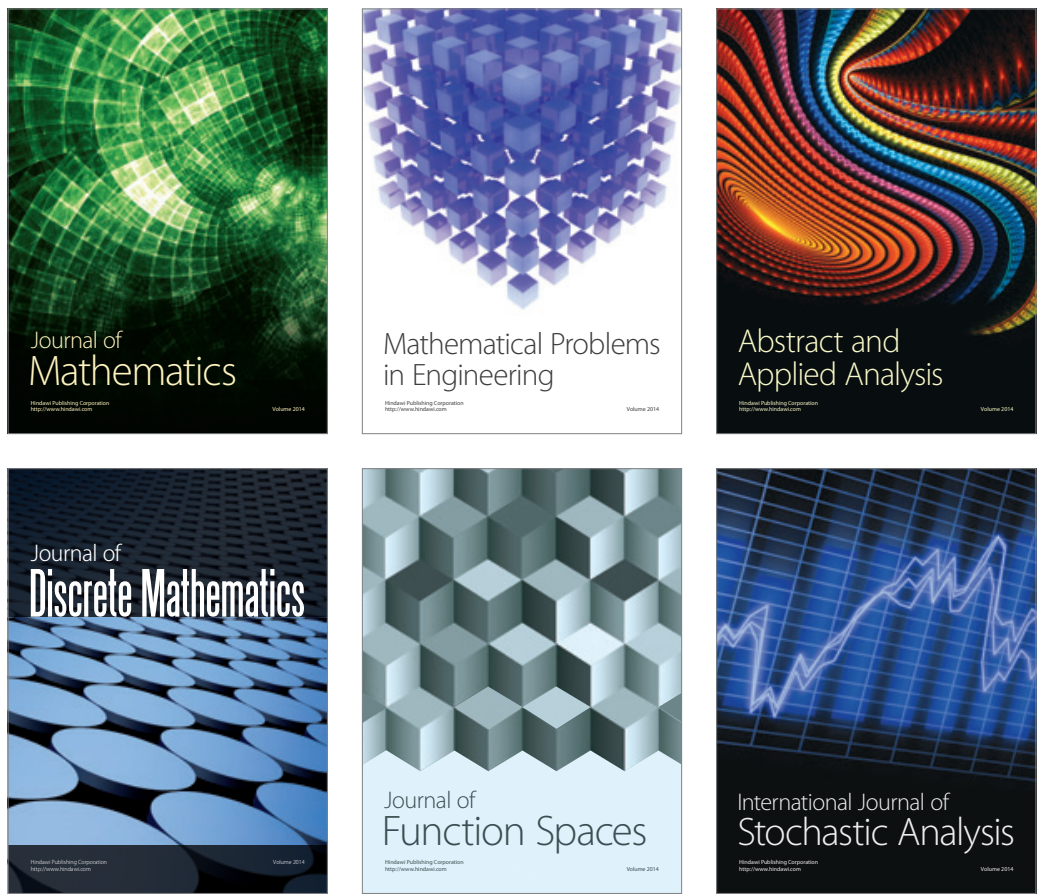

Journal of

Function Spaces

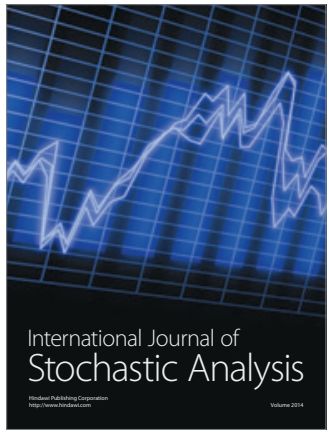

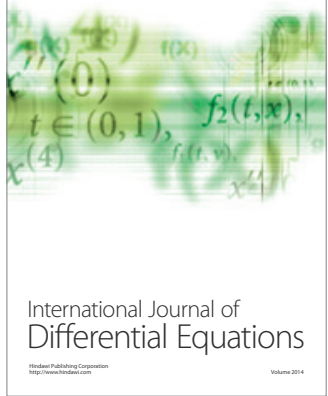
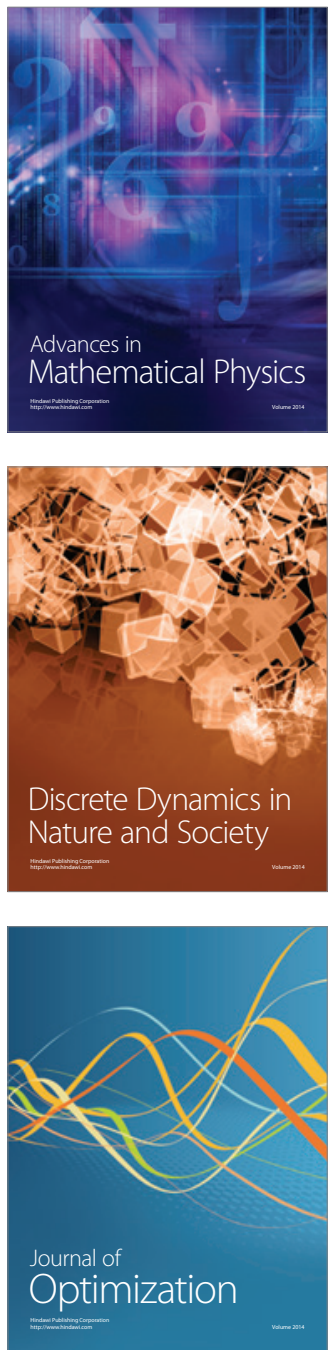